\title{
Effect of Natural and Synthesized Oil Blends with Diesel by Volume on Lubrication and Performance of Internal Combustion Engine
}

\author{
Laxman Palikhel $^{*}, 1$, Rupesh Lal Karn ${ }^{1}$, Suman Aryal ${ }^{1}$, and Barsha Neupane ${ }^{1}$ \\ ${ }^{1}$ Department of Automobile and Mechanical Engineering, Thapathali Campus, Institute of Engineering, \\ Tribhuvan University, Kathmandu, Nepal \\ *Corresponding Email: laxmanpalikhel@ioe.edu.np
}

\begin{abstract}
Use of ultra-low sulfur diesel leads to improve emission but it has negative impact on lubrication. Poor lubrication leads to damage the cylinder parts and piston rings. For proper lubrication in ultra-low sulfur diesel, anti-wear agent, corrosion \& Rust inhibitor, metal deactivator, Anti-oxidant, Pour point depressant, seal swell agent, viscosity improver and other are used. Viscosity improver such as polymers and copolymers of methacrylates, butadiene olefins and alkylated styrenes reduce the rate of viscosity change with temperature, metal deactivator are organic complexes containing nitrogen or sulphur, amines, sulphides and phosphites reduce catalytic effect on metals on oxidation rate, anti-wear agent such as Zinc dithiophosphates, organic phosphates and acid phosphates reduces friction and wear and prevent scoring and seizure. In this paper comparison of 5\% blend of commercially available synthesized lubricating oil mixed with pure diesel by volume and 5\% blend of transesterified Jatropha with pure diesel by volume is investigated. It is found that for the same brake power, indicated power provided by $5 \%$ blend of transesterified Jatropha is lower than 5\% blend of lubricating oil. The friction loss for 5\% blend of transesterified Jatropha is lower than 5\% blend of lubricating oil. Throughout the load specific fuel consumption of 5\% blend of transesterified Jatropha is lower than 5\% blend of lubricating oil except at low load (i.e. before $1.5 \mathrm{~kg}$ ). Other performance parameters such as indicated thermal efficiency, brake thermal efficiency, volumetric efficiency and mechanical efficiency also support the fact that 5\% blend of transesterified Jatropha shows a better performance characteristics than $5 \%$ blend of lubricating oil.
\end{abstract}

Keywords: Frictional Power, Low Sulfur Diesel, Lubricity, Biodiesel, Ultra-Low Sulfur Diesel

\section{INTRODUCTION}

In comparison of low sulfur diesel, Ultra-low sulfur diesel is regarded as a cleaner burning diesel fuel having a sulfur content that is about $97 \%$ less than that of low sulfur diesel fuel. As part of initiative to substantially lower the emission of particulate matter in diesel engine, in 2006 European Union has taken 
an initiative to replace low sulphur diesel by ultra-low sulfur diesel. Hydrodesulferization of diesel leads the diesel fuel to loss its lubricty. Though the loss of lubricity of the diesel fuel is observed with the removal of sulphur but it is mainly due to the loss of nitrogen and oxygen based polar trace compounds from diesel which are also removed in the due process of Hydrodesulferization. [1]

Hydrogenation deals with addition of hydrogen in compound. Hydrogenolysis is one of the type of hydrogenation that results in the removal of the $\mathrm{C}-\mathrm{X}$ chemical bond, where $\mathrm{C}$ denotes carbon atom and $\mathrm{X}$ denotes sulfur, nitrogen or oxygen atom. The outcome of a hydrogenolysis reaction is formation of $\mathrm{C}$ $\mathrm{H}$ and $\mathrm{H}-\mathrm{X}$ chemical bonds. Thus, hydrodesulfurization is a type of hydrogenolysis reaction. Ethanethiol $(\mathrm{C} 2 \mathrm{H} 5 \mathrm{SH})$ is a sulfur compound that is present in some petroleum refining stream. Hydrodesulfurization reaction can be expressed as:

\section{Ethanethiol + Hydrogen $\Rightarrow$ Ethane + Hydrogen Sulfide $\quad \mathrm{C} 2 \mathrm{H} 5 \mathrm{SH}+\mathrm{H} 2 \Rightarrow \mathrm{C} 2 \mathrm{H} 6+\mathrm{H} 2 \mathrm{~S}$}

Traditionally viscosity is an indicator for a fuel to provide wear protection against metal parts but for ultra-low sulfur diesel higher viscosity could cause severe adhesive wear in rotatory distributor pumps [2]. In the due course of improving lubricity property, biodiesel form a film to prevent mechanical contact between the two metal parts. [3]. [4] Noticed that he sulfur content has influence on diesel lubricity, low sulfur content gets worse lubricity, but this lubricity can be restored with biodiesel. He further stated that Biodiesel showed better friction reduction performances than the different commercial diesels. However, blends of biodiesel and diesel present similar tribological performance and can be used as an excellent fuel. Mixtures of 5 and $10 \%$ biodiesel with diesel fuel (without a conventional lubricity additive) have lubricity values that are similar to conventional automobile diesel fuel. [5]

[3] Studied the effects of biodiesel from palm and Jatropha oils on improving the lubricity properties of ultra-low sulfur via high-frequency reciprocating rig technique and found that Jatropha biodiesel is superior lubricity additive than palm biodiesel because of the presence of longer chains of fatty acid in Jatropha oil than that of palm oil and concluded that biodiesel can be used as a lubricity additive to ultralow sulfur diesel with as little as $0.25-0.5 \%$ blends.

\section{MATERIAL AND METHOD}

Test was performed on a single cylinder 4 stroke diesel engine. Detail specification is:

Power $3.50 \mathrm{~kW}$

RPM 1500, Constant Speed

Water Cooled Diesel Engine

Cylinder Bore 87.50( $\mathrm{mm})$

Stroke Length $110.00(\mathrm{~mm})$

Connecting Rod length $234.00(\mathrm{~mm})$

Compression Ratio 17.5

Swept volume 661.45 (cc)

Performance Parameters:

Orifice Diameter (mm): 20.00

Orifice Coefficient of Discharge: 0.60

Dynamometer Arm Length (mm): 185

Fuel Pipe diameter (mm): 12.40 
Ambient Temp. (Degree C): 27

Pulses Per revolution: 360

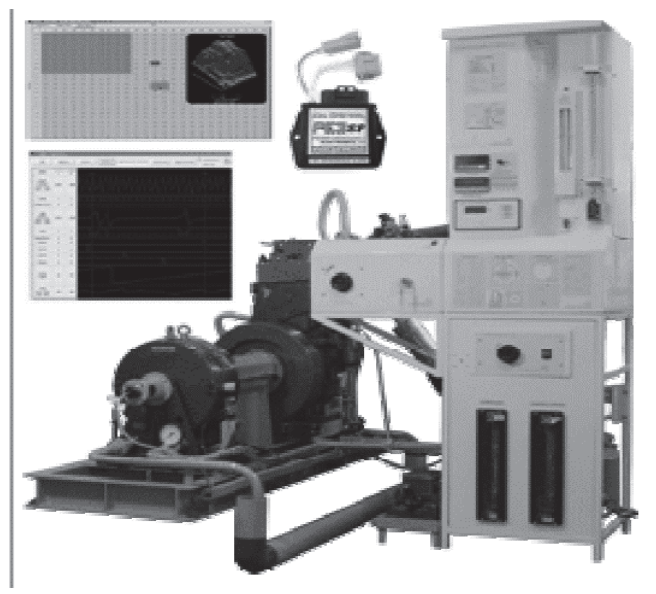

Figure 1: Test Engine

Used lubricating oil is Castrol Activ 4T 200W-40 having the enlisted property.

\begin{tabular}{|l|l|l|l|}
\hline Name & Method & Units & Typical \\
\hline Density @ $15^{\circ} \mathrm{C}$, Relative & $\begin{array}{l}\text { ASTM } \\
\text { D4052 }\end{array}$ & $\mathrm{g} / \mathrm{ml}$ & 0.88 \\
\hline Viscosity, Kinematic $100^{\circ} \mathrm{C}$ & ASTM D445 & $\mathrm{mm}^{2} / \mathrm{s}$ & 14.0 \\
\hline Viscosity, Kinematic $40^{\circ} \mathrm{C}$ & ASTM D445 & $\mathrm{mm}^{2} / \mathrm{s}$ & 120 \\
\hline Viscosity Index & ASTM & & 110 \\
& D2270 & & \\
\hline Total Base Number, TBN & ASTM & $\mathrm{mg} \mathrm{KOH} / \mathrm{g}$ & 9.58 \\
& D2896 & & \\
\hline
\end{tabular}

Transesterified Jatropha is used having the enlisted fuel property.

\begin{tabular}{|l|l|l|}
\hline Name & Unit & Value \\
\hline Density $@ 15^{\circ} \mathrm{C}$ & $\mathrm{Kg} / \mathrm{m}^{3}$ & 875 \\
\hline Viscosity, Kinematic $40^{\circ} \mathrm{C}$ & $\mathrm{m}^{2} / \mathrm{s}$ & 5.72 \\
\hline Calorific Value & $\mathrm{KJ} / \mathrm{Kg}$ & 39500 \\
\hline Flash Point & ${ }^{\circ} \mathrm{C}$ & 38 \\
\hline Fire Point & ${ }^{\circ} \mathrm{C}$ & 42 \\
\hline Cloud Point & ${ }^{\circ} \mathrm{C}$ & 14 \\
\hline
\end{tabular}




\section{EXPERIMENT OUTCOME.}

\subsection{PERFORMANCE RESULT}

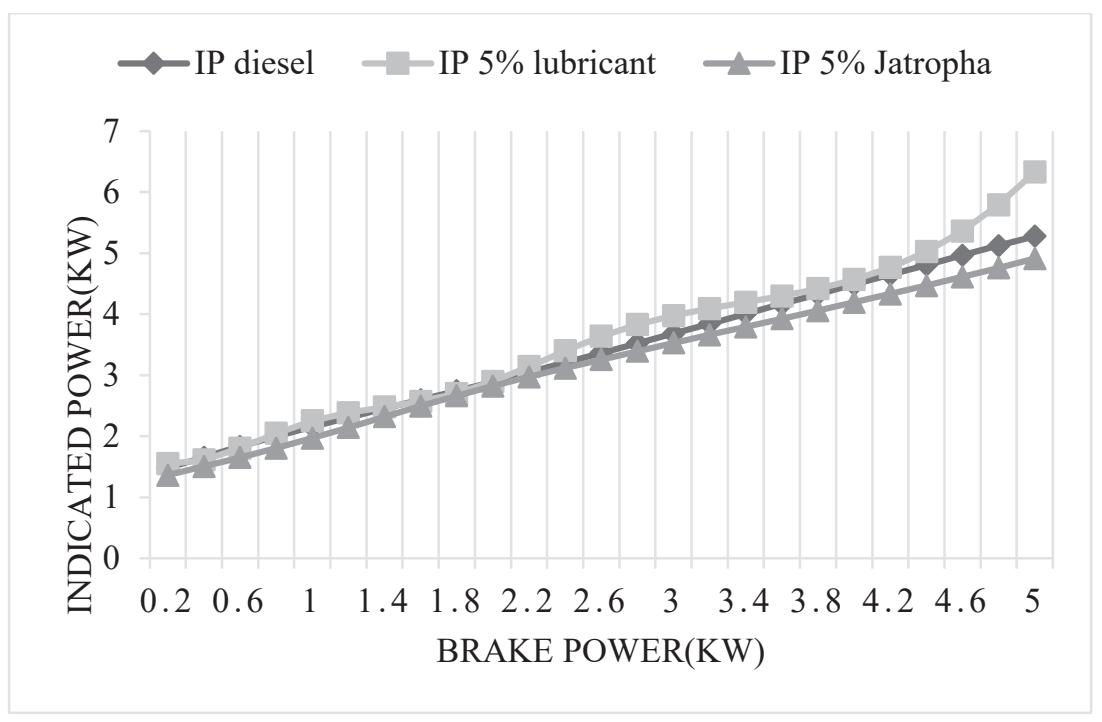

Figure 2: Indicated power vs Brake power

From the above figure, for the same brake power provided among diesel, 5\% lubricating oil blend with diesel and 5\% Jatropha oil blend with diesel, 5\% Jatropha blend with pure diesel by volume gives the same brake power with lower value of indicated power.

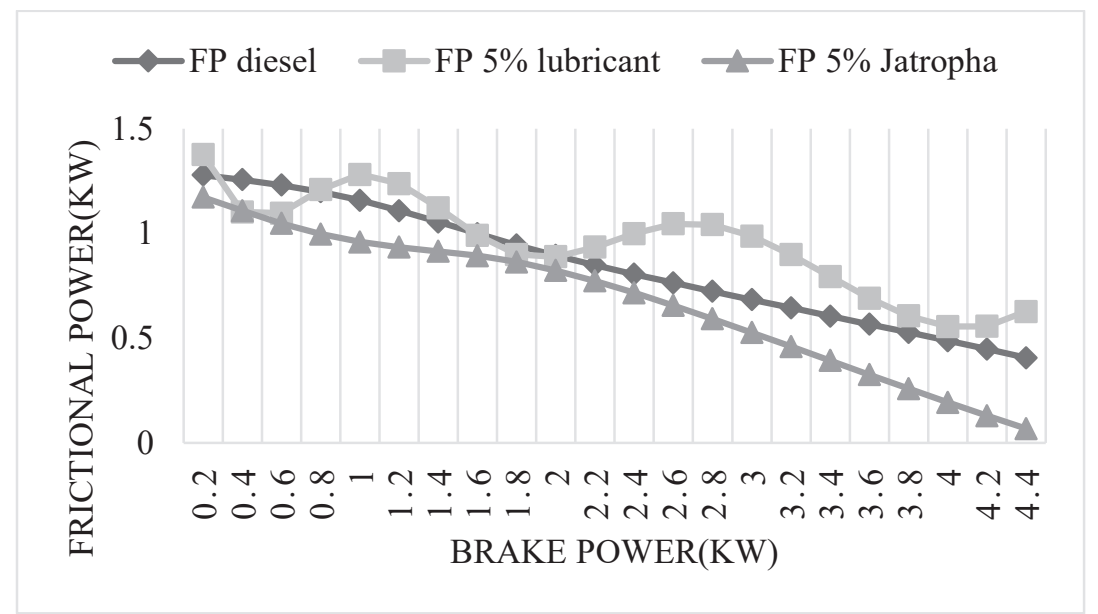

Figure 3: Frictional power vs Brake power

From the above figure, for the same brake power provided among diesel, 5\% lubricating oil blend with diesel and 5\% Jatropha oil blend with diesel, 5\% Jatropha blend with pure diesel by volume gives the 
same brake power at lower frictional power. This means frictional loss provided by $5 \%$ Jatropha blend with pure diesel is lower than 5\% lubricating oil blend with diesel and then pure diesel.

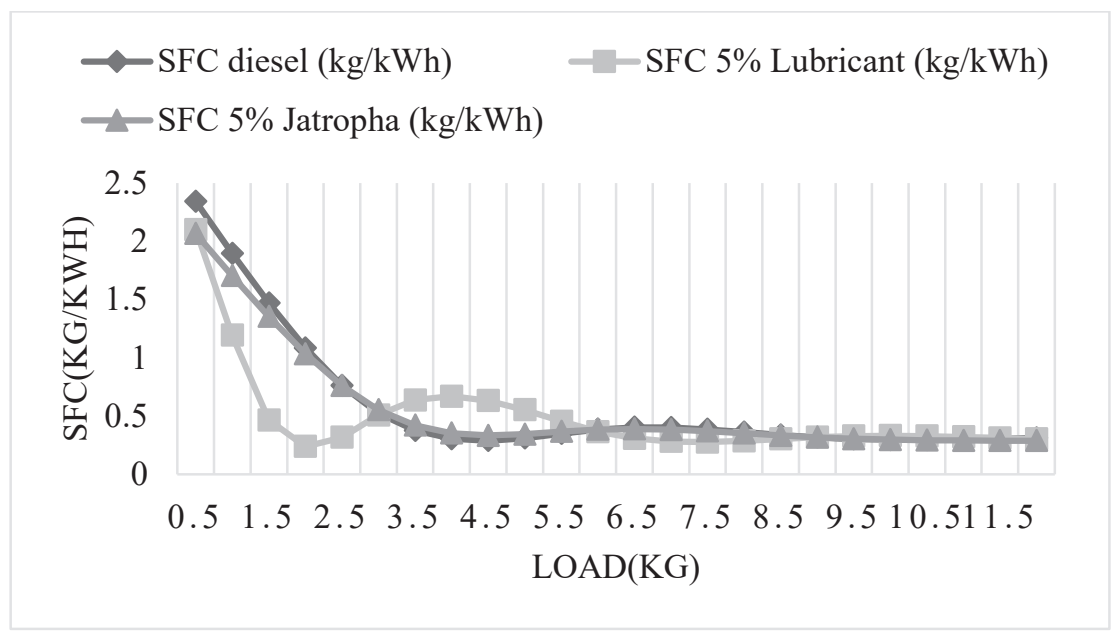

Figure 4: Specific fuel consumption vs Load

From the above figure it is found that at lower load, , 5\% lubricating oil blend with diesel shows the low specific fuel consumption. On the average throughout the load, 5\% jatropha blend with pure diesel by volume shows a lower specific fuel consumption among diesel, 5\% lubricating oil blend with diesel.

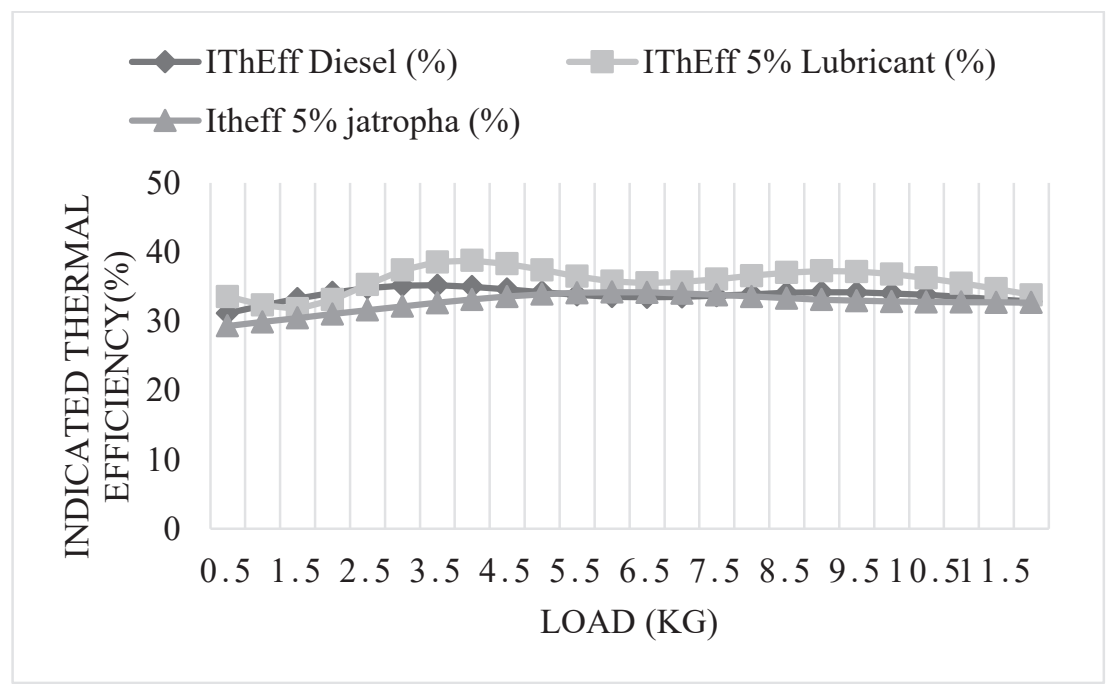

Figure 5: Indicated thermal efficiency vs Load

From the above figure it is shown that higher indicated thermal efficiency is shown by $5 \%$ lubricating oil blend with diesel among 5\% jatropha blend with pure diesel by volume and pure diesel. Indicated thermal efficiency shows what fraction of heat supplied is converted into indicated work. So from the 
figure it is found that 5\% lubricating oil blend with diesel by volume converts the formed heat into indicated work i.e. Higher indicated work is performed by $5 \%$ lubricating oil blend with diesel

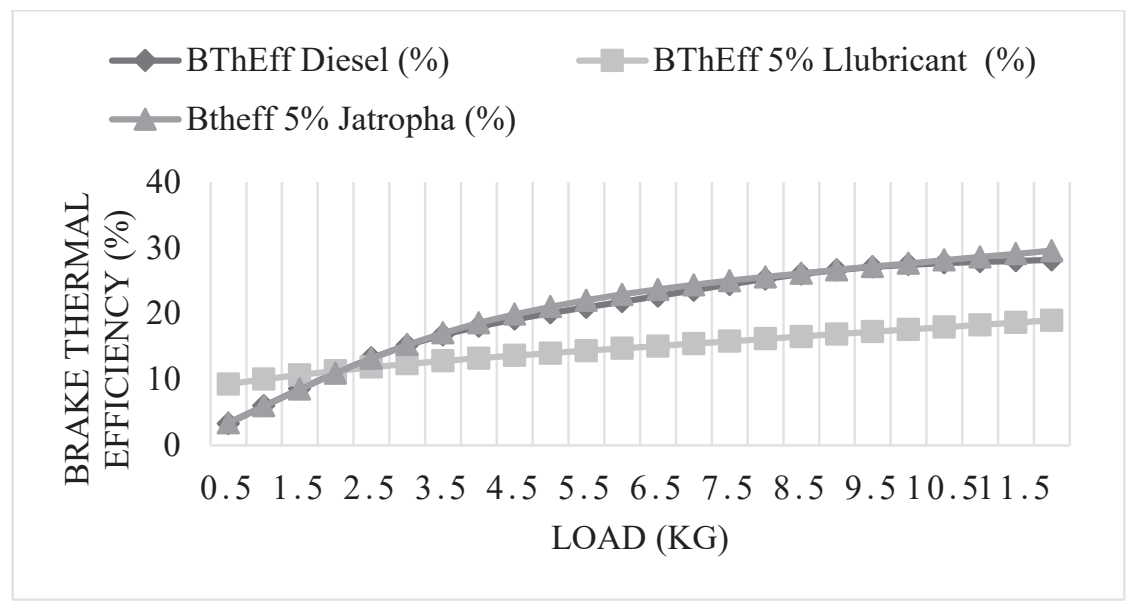

Figure 6: Brake thermal efficiency vs Load

From the above figure it is shown that at ow load, higher brake thermal efficiency is shown by $5 \%$ lubricating oil blend with diesel among 5\% jatropha blend with pure diesel by volume and pure diesel. But with the rise of load higher brake thermal efficiency is shown by $5 \%$ jatropha blend with pure diesel by volume. Brake thermal efficiency shows what fraction of heat supplied is converted into useful work i.e. Energy supplied to engine shaft. So from the figure it is found that $5 \%$ jatropha oil blend with diesel by volume converts the formed heat into useful work i.e. Higher useful work is performed by $5 \%$ jatropha oil blend with diesel by volume among 5\% lubricating oil blend with diesel and pure diesel.

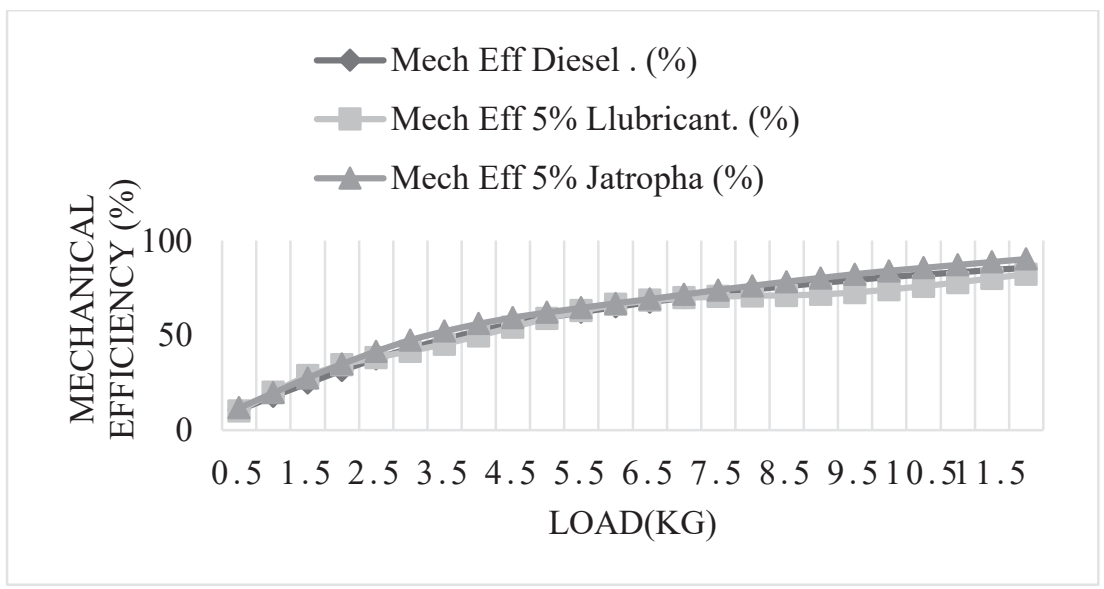

Figure 7: Mechanical efficiency vs Load

For a same brake power, mechanical efficiency is indirectly proportional to indicated power. From the above graph it is found that $5 \%$ jatropha blend with pure diesel by volume shows higher mechanical efficiency than $5 \%$ lubricating oil blend with diesel by volume and pure diesel. 


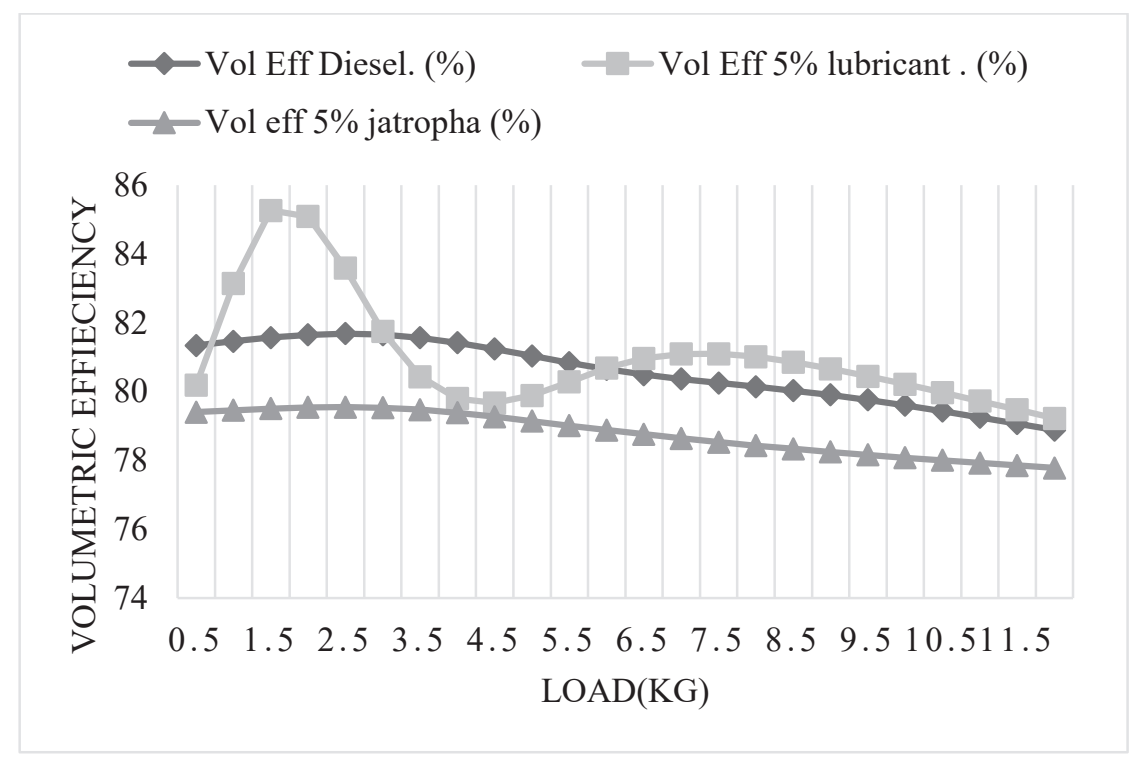

Figure 8: Volumetric efficiency vs Load

From the figure it is found that lower volumetric efficiency of that $5 \%$ jatropha blend with pure diesel by volume is lower than $5 \%$ lubricating oil blend with diesel by volume and pure diesel this means low volume of air is taken into cylinder for $5 \%$ jatropha blend with pure diesel by volume

\section{CONCLUSION}

$5 \%$ blend of Transesterified Jatropha with diesel shows better lubricating nature then 5\% blend of lubricating oil with diesel.

$>$ For the same breake power, $5 \%$ blend of Transesterified Jatropha with diesel shows lower specific fuel consumption, indicated power and frictional power.

$>$ Volumteric effeciency of 5\% blend of Transesterified Jatropha with diesel is lower than 5\% blend of lubricating oil with diesel and pure diesel this is due to low combustion temperature.

$>$ Mechanical effiency and brake thermal efficiency of 5\% blend of Transesterified Jatropha with diesel is lower than $5 \%$ blend of lubricating oil with diesel and pure diesel this shows a better performance characteristics shown by $5 \%$ blend of Transesterified Jatropha with diesel

\section{ACKNOWLEDGMENT}

We would like to thank Subodh Kumar Ghimire, head of department of Department of Automobile and Mechanical Enginerring for allowing the performce test in Automobile Laboratoruy of Thapathali Campus, Dr. Surya Prasad Adhikari for his assistance during the performnace test. 


\section{REFERENCES}

[1] M. A. Hazrat, M. G. Rasul and M. K. Khan, "Lubricity Improvement of the Ultra-low Sulfur Diesel Fuel with the Biodiesel," in The 7th International Conference on Applied Energy - ICAE2015, Australia, 2015.

[2] G. Anaastopoulos, E. Lois, S. Kalligeros and F. Zannikos, "Impact of oxygen and nitrogen compunds on the lubricity property of low sulfur diese fuels," Energy, pp. 415-426, 2005.

[3] S. Topaaiboul and N. Chollacoop, "Biodiesel as a lubricity for ultra low sulfur diesel," Songklanakarian Journal of science and Technology, pp. 153-156, 2010.

[4] S. e. M. Valdicleide, E. R. d. Vale Souza, . M. V. d. Araújo Oliveira and S. M. Alves, "Effect of Desulfurization of Diesel and its Blends with Biodiesel on Metallic Contact," Materials Research, pp. 82-88, 2014.

[5] M. Muñoz, F. Moreno, C. Monné, J. Morea and J. Terradillos, "Biodiesel improves lubricity of new low sulphur diesel fuels," Renewable Energy, pp. 2918-2924, 2011. 